\title{
Effect of Morphological Change of Carbide on Elongation of Boron-bearing Al-killed Steel Sheets
}

\author{
Y. FUNAKAWA, T. INAZUMI and Y. HOSOYA \\ Materials and Processing Research Center, NKK Corporation, Minamiwatarida-cho, Kawasaki-ku, Kawasaki, Kanagawa-ken \\ 210-0855 Japan.
}

(Received on October 10, 2000; accepted in final form on April 13, 2001)

\begin{abstract}
It has been reported that boron has a beneficial effect on the mechanical properties of continuously annealed Al-killed steel sheets. However, the effect of boron on elongation of boron-bearing steels had not been fully investigated. In this study, the effect of boron on elongation was investigated for boron-bearing Al-killed steel sheet by analyzing the substantial effects of fine carbides precipitating in matrix and at the grain boundaries.

Using scanning electron microscope and image analyzer, an investigation was made for the precipitation site and the size distribution of fine carbides caused by the variation of excess boron and over-aging temperature. The effects of fine carbides on the tensile elongation of the steels were examined. The carbide morphology and the precipitation site changed with excess boron since the excess boron accelerated carbide precipitation in matrix by segregating at the grain boundaries. In the case where uniform elongation and post-uniform elongation were evaluated by $n$-value and $m$-value respectively, $n$-value decreased with increasing amount of fine carbides in matrix. Furthermore, excess boron deteriorated $n$-value irrespective of carbide morphology. On contrast, $m$-value rose with a decrease in the diameter of carbide at the grain boundary irrespective of small amount of excess boron. It was indicated that the deterioration of elongation by the small amount of excess boron was caused by a decrease in uniform elongation, which might be attributed to fine carbides in matrix and boron in solution.
\end{abstract}

KEY WORD: boron; continuously annealed sheet; elongation; $n$-value; $m$-value; carbide morphology.

\section{Introduction}

The effects of boron addition on the mechanical properties of continuously annealed boron-bearing Al-killed steel sheet have been widely studied. It has been reported that boron addition increases the total elongation of Al-killed steel sheets by improving the grain growthability by substituting large $\mathrm{BN}$ for $\mathrm{AlN}$, and that maximum elongation can be attained by optimizing the boron/nitrogen ratio. ${ }^{1-3)}$ The deterioration of elongation, when there is the larger boron content than the nitrogen content, has been considered to be attributed to grain refinement caused by existence of excess boron or by fine precipitation of $\mathrm{Fe}_{23}(\mathrm{CB})_{6}$ in previous research $^{1,4)}$ on the steel containing more than $10 \mathrm{ppm}$ boron in solution. However, the deterioration of elongation by the grain refinement can be explained only in the steel containing a large amount of boron in solution. Small amount of boron in solution does not cause grain refinement in low carbon steel, and also the precipitation of $\mathrm{Fe}_{23}(\mathrm{CB})_{6}$ has only been observed in high temperature coiled hot-band. ${ }^{4,5)}$

On the other hand, it has been reported that carbide morphology, which affects elongation, ${ }^{6}$ ) is changed by boron addition. ${ }^{7)}$ Thereby it can be considered that the change in carbide morphology by excess boron might be the reason for the deterioration in elongation of boron-bearing low carbon steel.
In this report, the relationship between elongation and carbide morphology has been investigated and quantitative analyses of carbides has been conducted to explain the deterioration in elongation of boron-bearing Al-killed steel sheet which contains small amount of excess boron.

\section{Experimental Procedure}

The chemical compositions of steels used in this investigation are shown in Table 1. The carbon content was fixed around a level of $0.015 \%$, which is approaching the solubility limit of carbon in ferrite at annealing temperature. Carbide morphology and amount of carbon in solution were changed greatly by primary cooling and over-aging treatment. Boron was added to scavenge nitrogen by forming $\mathrm{BN}$ that precipitates in matrix. ${ }^{8)}$ Excessive amount of nitrogen, which did not combine with boron, existed in steel A, either remaining as in solid solution or precipitating as AlN. In contrast, a small amount of excess boron in solution remained in steel $\mathrm{B}$.

These materials were prepared as $1.0 \mathrm{~mm}$ thick coldrolled sheets, which had been coiled at $640^{\circ} \mathrm{C}$ in hot-rolling process. Subsequently, the cold-rolled sheets were annealed in salt baths according to the cycles shown in Fig. 1 to obtain some kind of carbide morphology. 9,10 ) 
Table 1. Chemical compositions of steels used. (mass \%)

\begin{tabular}{|c|c|c|c|c|c|c|c|c|c|c|c|}
\hline & $C$ & $S i$ & $M n$ & $P$ & $S$ & $A l$ & $N$ & $B$ & $B / N$ & Excess N & Excess B \\
\hline Steel A & 0.014 & 0.01 & 0.13 & 0.008 & 0.006 & 0.019 & 0.0033 & 0.0024 & 0.95 & 0.00018 & - \\
\hline Steel B & 0.017 & 0.01 & 0.13 & 0.014 & 0.010 & 0.002 & 0.0019 & 0.0017 & 1.16 & - & 0.00023 \\
\hline
\end{tabular}
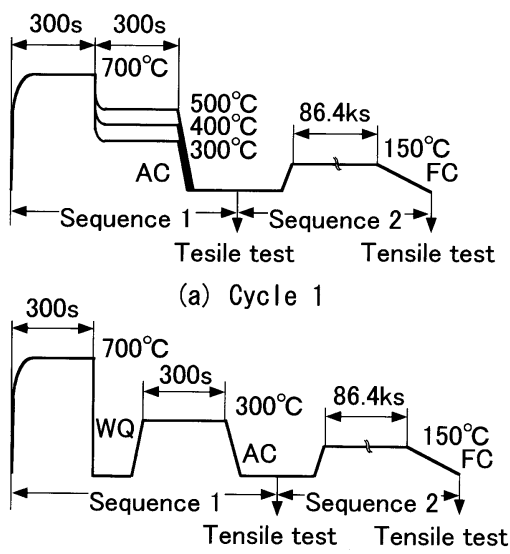

(b) Cycle 2

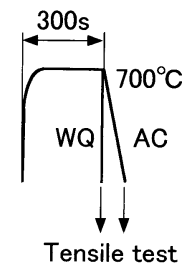

(c) Cycle 3

Fig. 1. Schematic diagram of annealing and carbon precipitation treatment.

(A) Cycle 1

Sequence 1: the soaking temperature was fixed at $700^{\circ} \mathrm{C}$ for $300 \mathrm{~s}$ to completely dissolve coarse cementites that had been present in the hot-band. During the cooling process the materials were over-aged by maintaining the temperature at fixed levels of $500^{\circ} \mathrm{C}, 400^{\circ} \mathrm{C}$ and $300^{\circ} \mathrm{C}$ for $300 \mathrm{~s}$ in order to change carbide morphology.

Sequence 2: a few of the over-aged materials were kept at $150^{\circ} \mathrm{C}$ for $86.4 \mathrm{ks}$. This was followed by furnace cooling to precipitate carbon retained in solution completely.

(B) Cycle 2

Sequence 1: the soaking process was exactly same as that of cycle 1. The materials were water quenched from the soaking temperature and then reheated at $300^{\circ} \mathrm{C}$ to obtain very fine carbides.

Sequence 2: some of the over-aged materials were kept at $150^{\circ} \mathrm{C}$ for $86.4 \mathrm{ks}$ to precipitate carbon retained in solution completely.

(C) Cycle 3

The materials were water quenched or air cooled from the soaking temperature in order to retain much carbon in solution.

After these cycles, internal friction measurements were carried out to determine the amount of carbon in solution in each material. Temper rolling with the elongation of $1.5 \%$ was carried out in order to prevent yield-point elongation.

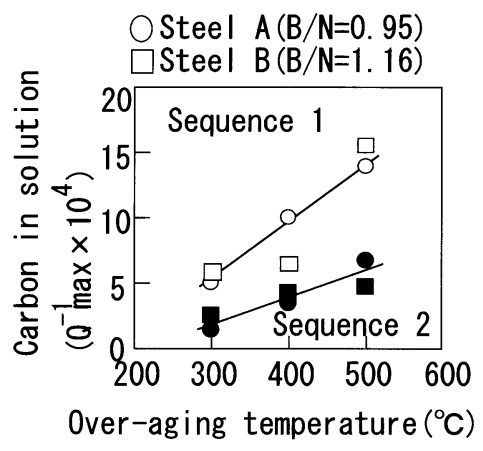

Fig. 2. Change in carbon in solution after sequences 1 and 2 under heat treatment of cycle 1 .

ASTM-type tensile specimens of $50 \mathrm{~mm}$ gauge length and of $12.5 \mathrm{~mm}$ gauge width were prepared so that the length of the samples was along the rolling direction. Changes in carbide morphology were observed by using a scanning electron microscope and quantified by image analyses.

In the present work, the effect of grain size on the mechanical properties could be ignored since grain sizes of both steels were at the same level, about $18 \mu \mathrm{m}$.

\section{Results}

\subsection{Change in Amount of Carbon in Solution and Carbide Morphology during Heat Treatment}

Change in amount of carbon in solution $\left(Q_{\max }^{-1}\right)$ measured by internal friction is shown in Fig. 2. All of the materials were over-aged in the cycle 1 shown in Fig. 1. The amount of carbon in solution in the materials after sequence 1 significantly decreased with the over-aging temperature since low temperature over-aging accelerated carbide precipitation. Furthermore, after sequence 2, the amount of carbon in solution was decreased below $5 \times 10^{-4}$ in $Q_{\max }^{-1}$. This change in the amount of carbon in solution by the carbide precipitation treatment was greater when the materials were over-aged at the higher temperature.

Typical SEM (Secondary Electron Microscope) images of carbide precipitated in steels A and B are shown in Figs. 3 and $\mathbf{4}$, respectively. The carbides and ferrite grain boundaries can be seen. Only a few carbides were observed in the materials that were not over-aged after water quenching. This indicates that almost all of cementites in the hot-band might dissolve during annealing. In steel A over-aged at $500^{\circ} \mathrm{C}$, coarse carbides were precipitated mostly at the grain boundaries. Subsequently fine carbides became apparent within matrix at lower over-aging temperature. The smallest carbides were observed in the material which was water quenched before over-aging at $300^{\circ} \mathrm{C}$. In steel B overaged at $500^{\circ} \mathrm{C}$, there were coarse carbides in matrix. Those carbides became fine at lower over-aging temperature. 
(a)

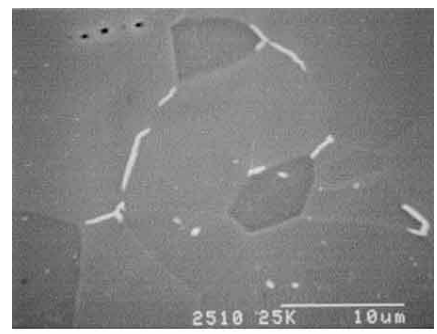

(b)

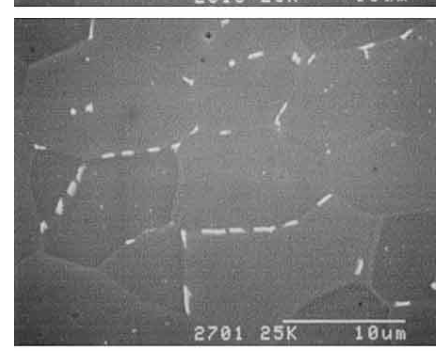

(c)

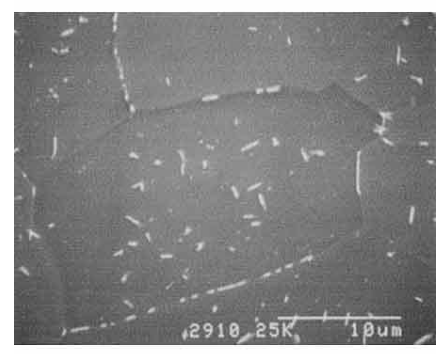

(d)

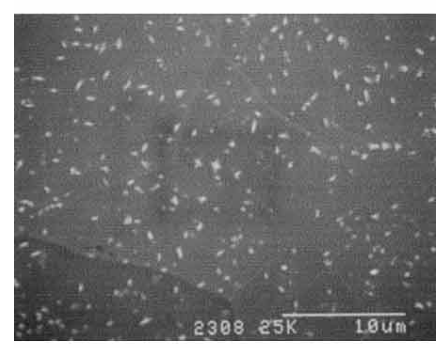

(e)

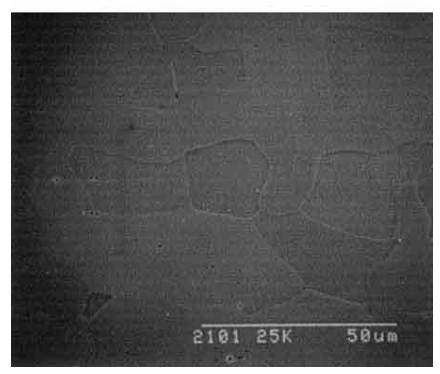

Fig. 3. Scanning electron micrographs showing the change in carbide morphology in steel without excess boron.
(a) Cycle 1: $500^{\circ} \mathrm{C} \mathrm{OA}$
(c) Cycle 1: $300^{\circ} \mathrm{C} \mathrm{OA}$
(b) Cycle 1: $400^{\circ} \mathrm{C} \mathrm{OA}$
(e) Cycle 3: WQ
(d) Cycle $2: \mathrm{WQ} \rightarrow 300^{\circ} \mathrm{C}$ OA

Here, image analyses were carried out to estimate the change in carbide morphology in matrix and at the grain boundaries with scanning electron micrographs for ten different areas in each material. In the analyzing process, carbides at the grain boundaries were distinguished from that in matrix on the micrographs. Figure 5 shows the size distribution of the carbides in the steels subjected to the carbide precipitation treatment. The carbide was assumed to be a circle when carbide diameter was measured. The diameter of carbide at the grain boundary in steel A over-aged at $500^{\circ} \mathrm{C}$ was in the range of $0.5 \mu \mathrm{m}$ to $2.8 \mu \mathrm{m}$. When the over-aging temperature was lower, the carbides became smaller so that the distribution range became narrow. In (a)

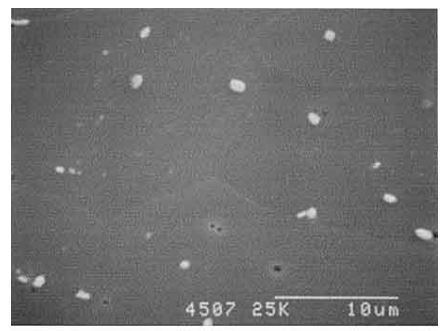

(b)

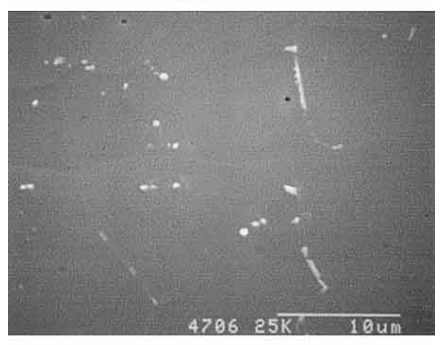

(c)

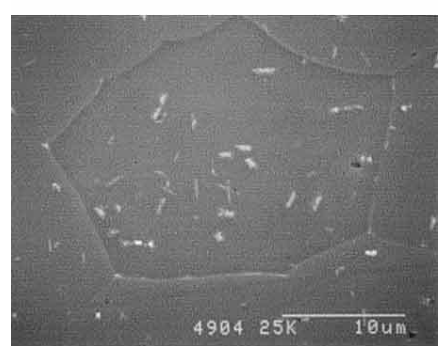

(d)

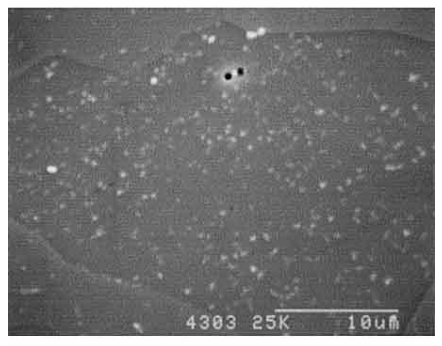

(e)

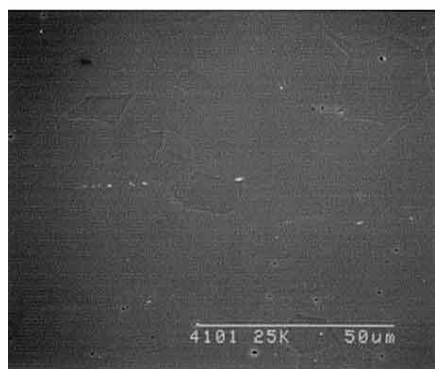

Fig. 4. Scanning electron micrographs showing the change in carbide morphology in steel containing excess boron.
(a) Cycle 1:500 ${ }^{\circ} \mathrm{C} \mathrm{OA}$
(b) Cycle 1: $400^{\circ} \mathrm{C} \mathrm{OA}$
(c) Cycle 1: $300^{\circ} \mathrm{C} \mathrm{OA}$
(d) Cycle 2: $\mathrm{WQ} \rightarrow 300^{\circ} \mathrm{C} \mathrm{OA}$
(e) Cycle 3: WQ

particular, there seemed to be only a few carbides in the water-quenched materials. In contrast, the volume fraction of carbides in matrix increased by lower temperature overaging and by water quenching. In steel B, the volume fraction of carbides at the grain boundaries was smaller than that in steel A so that the amount of carbides in matrix was larger than that in steel A.

Figure 6 shows change in the mean carbide diameter by varying the over-aging temperature. The mean diameter of carbide at the grain boundary in steel A was larger than that in matrix when the material was over-aged at $500^{\circ} \mathrm{C}$. In steel $\mathrm{B}$, the mean diameter of carbide at the grain boundary was as large as that in matrix. The mean carbide diame- 


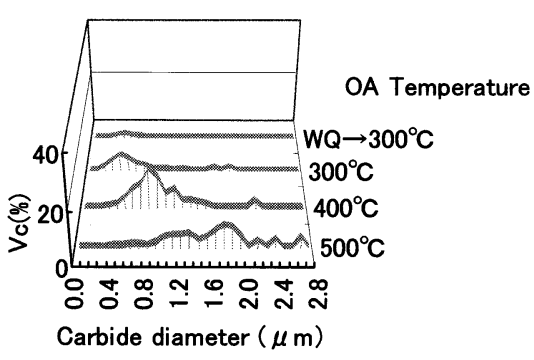

(a) Steel A, Grain boundary

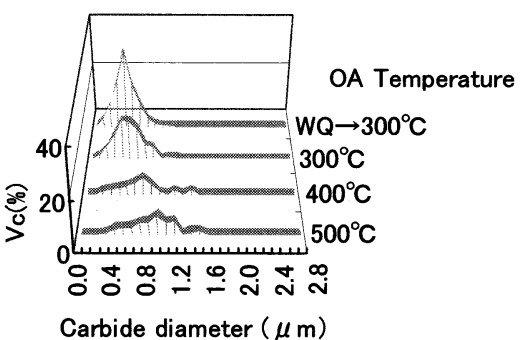

(b) Steel A, Matrix

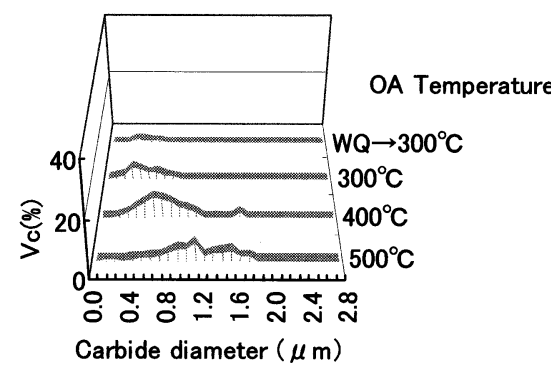

(c) Steel B, Grain boundary

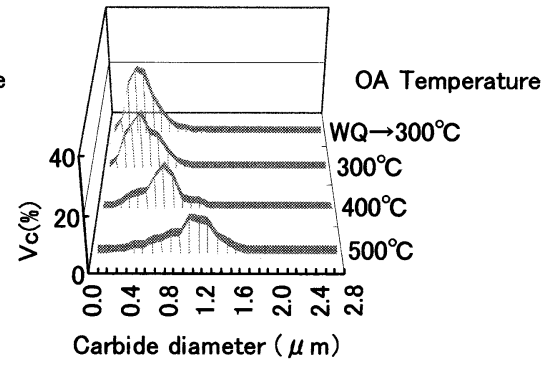

(d) Steel B, Matrix

Fig. 5. Effect of over-aging temperature on distribution of carbide diameter in matrix and at grain boundary.

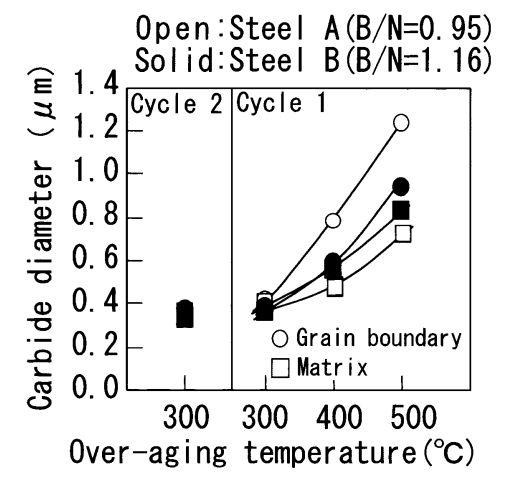

Fig. 6. Change in mean carbide diameter with decreasing overaging temperature.

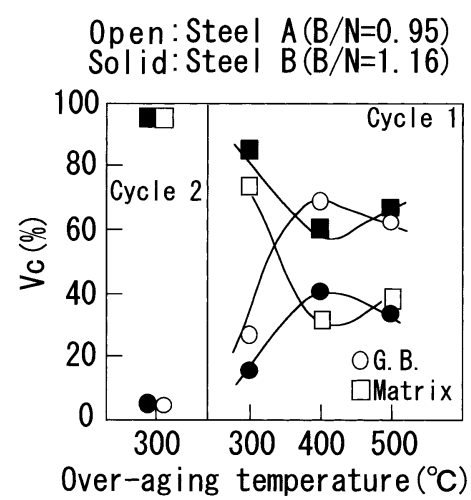

Fig. 7. Change in volume fraction of carbides with decreasing over-aging temperature.

ter decreased with the lower over-aging temperature so that the smallest one was obtained when the materials were over-aged at $300^{\circ} \mathrm{C}$ in both steels. Figure 7 shows change in the carbide volume fraction as a function of over-aging temperature. In steel $\mathrm{A}$, around $60 \%$ to $70 \%$ of carbides were precipitated at the grain boundaries when the materi- als were over-aged at the higher temperature. The volume fraction of carbides at the grain boundaries in steel A decreased to around $20 \%$ to $30 \%$ when the material was over-aged at $300^{\circ} \mathrm{C}$. The minimum volume fraction of carbides at the grain boundaries was attained in the waterquenched material so that the volume fraction of carbides in matrix became the maximum. In contrast, in steel B, the volume fraction of carbides in matrix was larger than that at the grain boundaries, even at the higher over-aging temperature. The volume fraction of carbides in matrix rose at lower over-aging temperature, after showing a small peak at $400^{\circ} \mathrm{C}$, so that more than $95 \%$ of carbides precipitated in matrix when the material was water quenched before overaging.

\subsection{Effect of Excess Boron on Relationship between Elongation and Over-aging Temperature}

The work hardening exponent ( $n$-value) has been generally used for estimation of uniform elongation. ${ }^{11)} \mathrm{N}$-value was measured from the loads at the tensile strain of $10 \%$ to $20 \%$. $M$-value is the strain rate sensitivity parameter, ${ }^{12}$ ) which has generally been used for estimation of the localization of the strain during diffuse necking; this parameter is defined as

$$
m=\ln \left(\sigma_{2} / \sigma_{1}\right) / \ln \left(\dot{\varepsilon}_{2} / \dot{\varepsilon}_{1}\right)
$$

where $\sigma_{1}, \sigma_{2}$ : loads before and after strain rate changing, respectively $\dot{\varepsilon}_{1}, \dot{\varepsilon}_{2}:$ strain rates.

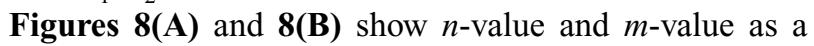
function of over-aging temperature, respectively. In both steels $\mathrm{A}$ and $\mathrm{B}, n$-value decreased with the over-aging temperature (Cycle 1). In the water-quenched materials before the over-aging treatment (Cycle 2), $n$-value was lower than that of the materials without water quenching so that $n$ value of steel A was higher than that of steel B for all of the 


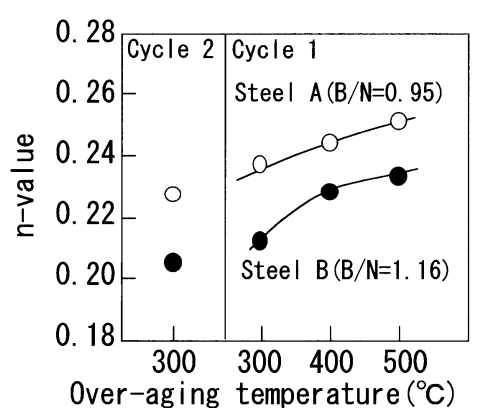

(a) n-value

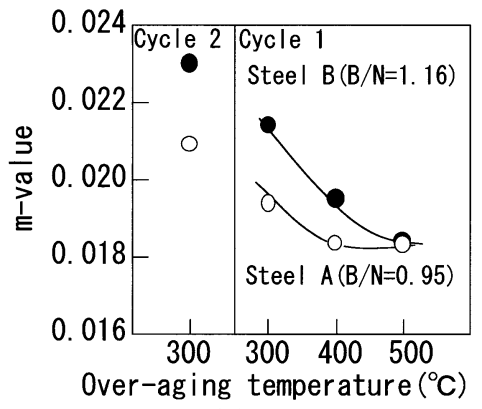

(b) m-value

Fig. 8. Change in $n$-value and $m$-value of boron-bearing Alkilled steel sheet with decreasing over-aging temperature.

over-aging temperatures. On contrast, $m$-value increased with a decrease in the over-aging temperature (Cycle 1 and 2 ). Furthermore, $m$-value of steel $\mathrm{B}$ was higher than that of steel A for all of the over-aging temperatures.

\section{Discussion}

\subsection{Acceleration of Carbide Precipitating in Matrix by Excess Boron}

In Figs. 6 and 7, it was shown that carbide precipitated at grain boundary by high temperature over-aging and that both low temperature over-aging and existence of excess boron accelerated carbide precipitation into matrix. The acceleration by low temperature over-aging may be explained by supersaturation of carbon in solution before over-aging treatment as in the previous work. ${ }^{13)}$ The acceleration of carbide precipitation into matrix by excess boron can be explained by segregation of boron at the grain boundaries.

In addition, to investigate the carbide-precipitating site in matrix, relationship between carbide and $\mathrm{BN}$ in matrix was compared. Figure 9 shows $\mathrm{BN}^{-}$and $\mathrm{C}^{-}$secondary ion images observed by SIMS (Secondary Ion Mass Spectroscopy). Almost the same distribution was observed in steel $\mathrm{B}$ for $\mathrm{BN}$ and $\mathrm{Fe}_{3} \mathrm{C}$. Furthermore, Fig. 10(a) shows carbides in $\mathrm{Cs}^{+}$sputtered matrix of steel B over-aged at $300^{\circ} \mathrm{C}$. Figure $10(\mathrm{~b})$ shows EDX spectra in and around the particle. A dark contrast with the diameter of $300 \mathrm{~nm}$ can be seen in the carbide. This is considered to be $\mathrm{BN}$ from EDX spectra. These results suggest that $\mathrm{BN}$ can become nucleation site for carbide in the steel containing a few ppm boron since $\mathrm{BN}$ is thought to have precipitated already in hot-band. ${ }^{14)}$

\subsection{Effect of Carbon in Solution on Elongation of Boron-bearing Al-killed Steel Sheet}

Figure 11 shows total elongation and uniform elongation

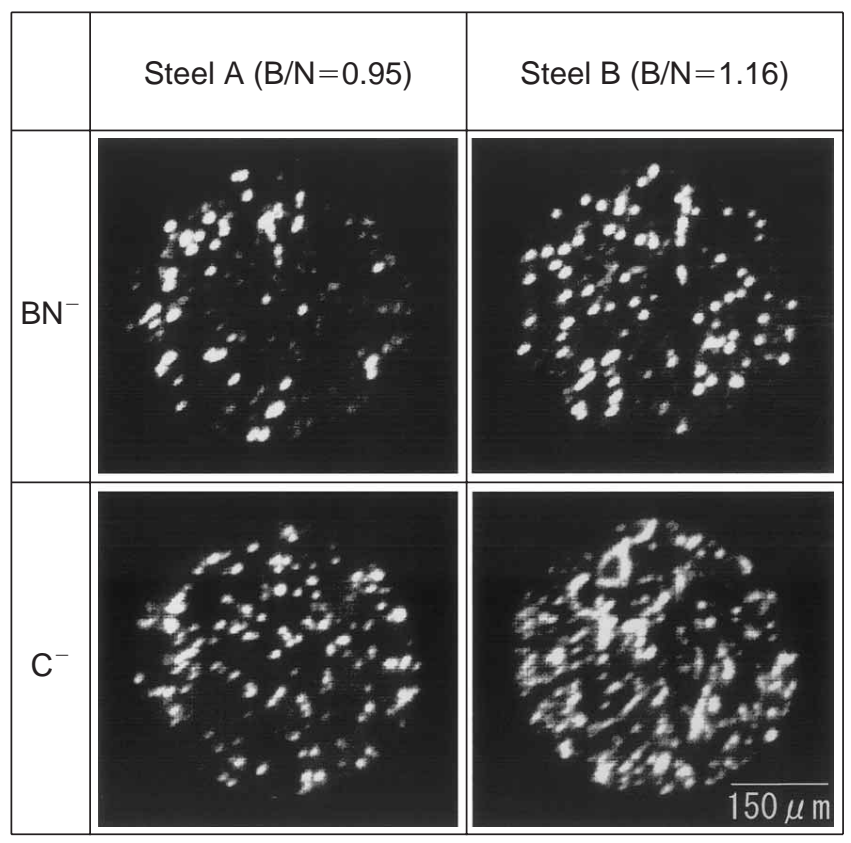

Fig. 9. Secondary ion images showing the distribution of $\mathrm{BN}$ and $\mathrm{Fe}_{3} \mathrm{C}$.

(a)

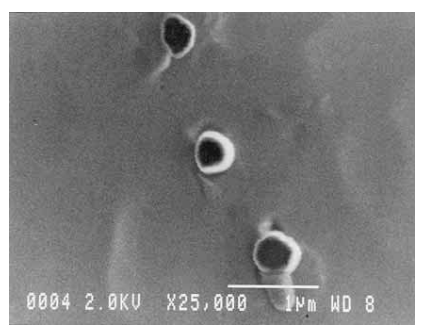

(b)

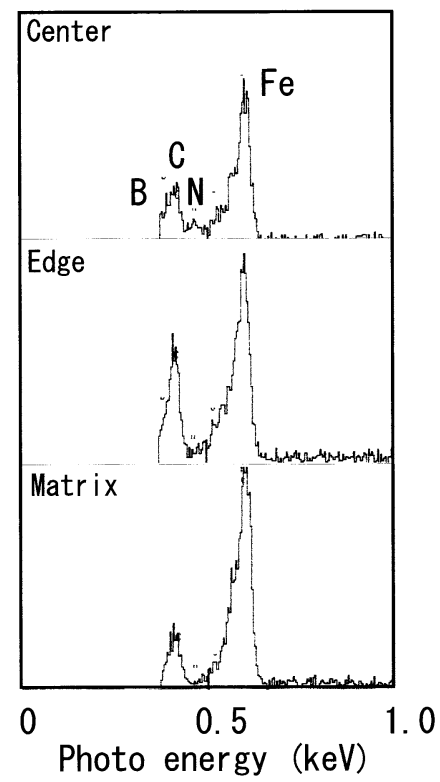

Fig. 10. Scanning electron micrograph and EDX spectra of precipitate in matrix of steel containing excess boron.

(a) Secondary electron micrograph showing fine carbides in matrix.

(b) EDX spectra of precipitate and matrix.

on stress-strain curve as a function of carbon in solution. Both total elongation and uniform elongation rose with a decrease in carbon in solution. This increase in elongation may involve not only the effect of a decrease in carbon in 
Table 2. Comparison of the results of the effect of the carbon in solution on the ductility of boron-bearing Al-killed steel sheets studied by Stephenson and Hosoya.

\begin{tabular}{|l|c|c|}
\hline & Uniform-elongation & Total-elongation \\
\hline Present work & $-0.26 \% /$ unit $\left(Q^{-1} \times 10^{4}\right)$ & $-0.53 \% /$ unit $\left(Q^{-1} \times 10^{4}\right)$ \\
\hline Stephenson & $-0.08 \% /$ unit $\left(Q^{-1} \times 10^{4}\right)$ & $-0.15 \% /$ unit $\left(Q^{-1} \times 10^{4}\right)$ \\
\hline Hosoya et. & $-0.09 \% /$ unit $\left(Q^{-1} \times 10^{4}\right)$ & $-0.3 \% /$ unit $\left(Q^{-1} \times 10^{4}\right)$ \\
\hline
\end{tabular}

- Cycle 3

$\Delta \Delta$ Cycle 1, 2

Before carbide precipitation treatment.

$\square$ Cycle 1,2

After carbide precipitation treatment.

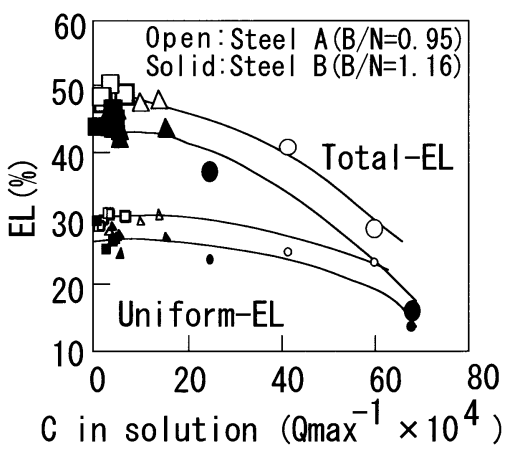

Fig. 11. Effect of carbon in solution on elongation of boronbearing Al-killed steel sheet.

solution, but also the effect of change in carbide morphology. Both total elongation and uniform elongation were saturated below carbon content of $10 \times 10^{-4}$. As a consequence it is indicated that carbon in solution remaining after the carbide precipitation treatment in Fig. 2 (sequence 2) does not affect the elongation. In addition, the effect of carbon in solution on total elongation and uniform elongation is compared with the results of either Stephenson ${ }^{15)}$ or Hosoya ${ }^{6)}$ in Table 2. The influence of carbon in solution on total elongation and uniform elongation was twice or three times larger than the previous works. This might be attributed to the change in carbide morphology by boron addition since the difference between the present work and their works was boron addition in the chemical compositions.

Figures 12 and 13 show change in $n$-value as a function of carbon in solution. Figure 13 is zooming up the range of small amount of carbon in solution in Fig. 12. It can be seen that $n$-value decreased slightly with carbon in solution when the amount of carbon in solution was higher than $20 \times 10^{-4}$. This decrease in $n$-value might be caused by the change in carbide morphology and quantity during cooling after soaking since $n$-value is irrespective of carbon in solution. ${ }^{15)}$ There was no significant difference between steel A and steel B when the amount of carbon in solution was more than $20 \times 10^{-4}$. Subsequently, $n$-value decreased significantly with carbon in solution when the amount of carbon in solution was less than $20 \times 10^{-4}$. This deterioration of $n$-value by decreasing the amount of carbon in solution is in good agreement with the previous work. ${ }^{6)}$ The deterioration of $n$-value by excess boron will be discussed in the following section on the basis of the quantitative analyses of the carbides.
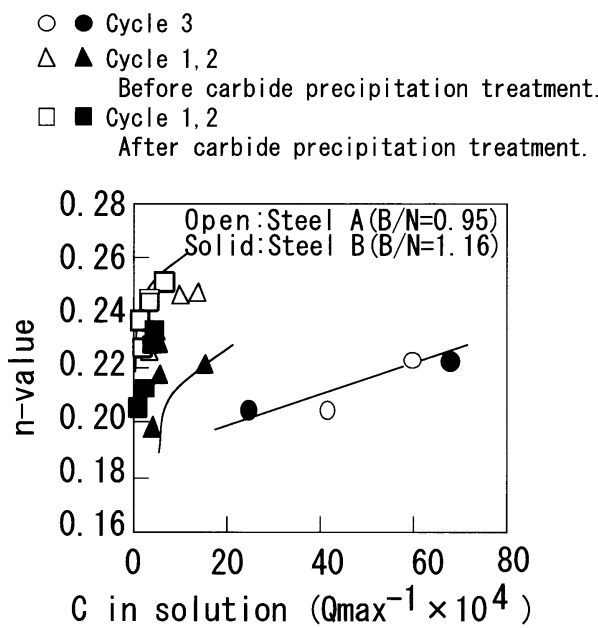

Fig. 12. Effect of carbon in solution on $n$-value of boron-bearing Al-killed steel sheet.

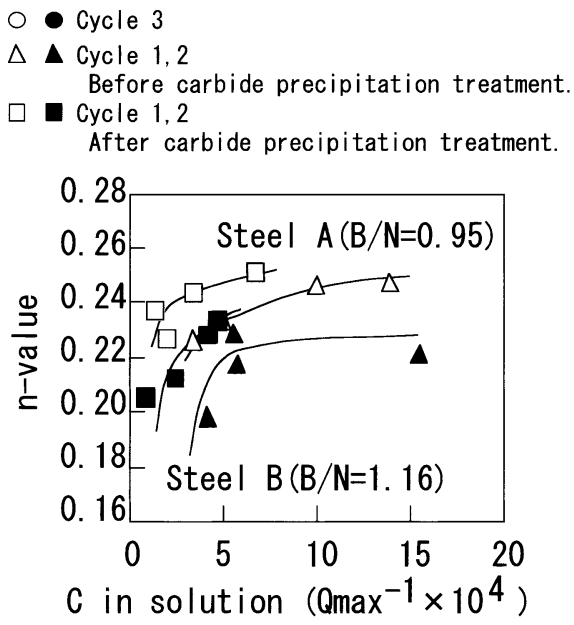

Fig. 13. Change in $n$-value with decreasing carbon in solution.

\subsection{Effect of Carbide Morphology on $n$-value and $m$ - value}

In the previous section, it was mentioned that the effect of carbon in solution on elongation might be ignored when the amount of carbon in solution was less than $10 \times 10^{-4}$. In this section, the effect of excess boron and carbide morphology on the elongation is discussed for the materials subjected to the carbide precipitation treatment.

In the previous work, ${ }^{6}{ }^{6}$ it had been reported that $n$-value and $m$-value were governed by carbide morphology in conventional continuously annealed Al-killed steel sheet. Figure 14 shows $n$-value and $m$-value rearranged as a function of the carbide diameter to investigate the reason for the change in $n$-value and $m$-value. $N$-value was plotted for the mean diameter of carbide in matrix because $n$-value closely related to dislocation structure. When the carbide diameter was larger than $0.5 \mu \mathrm{m}, n$-value decreased slightly with the carbide diameter. When the carbide diameter was less than $0.5 \mu \mathrm{m}, n$-value decreased dramatically in both steels. This behavior is in good agreement with that of conventional Alkilled steel sheet although carbides in matrix had not been distinguished from those at the grain boundaries in the previous study. This is caused by the fact that carbide precipitation in matrix occurs with the refinement of carbide at 


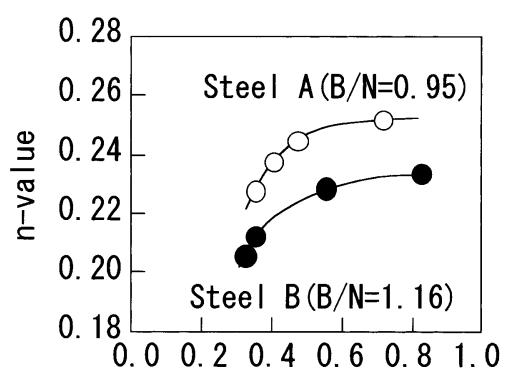

Carbide diameter in matrix $(\mu \mathrm{m})$

Fig. 14. Effect of carbide diameter on $n$-value of boron-bearing Al-killed steel sheet.

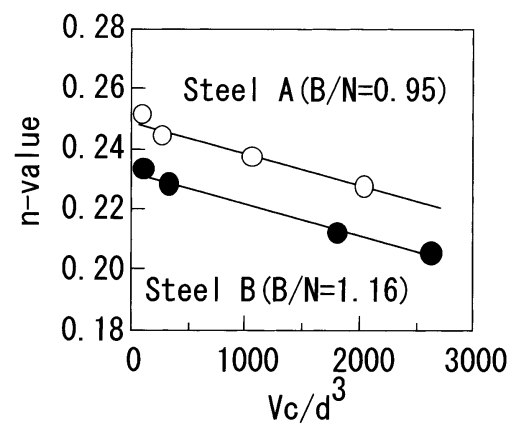

Fig. 15. Change in $n$-value with increasing carbide density $\left(V c / d^{3}\right)$ in matrix.

lower over-aging temperature. This change in $n$-value, however, can hardly be explained only by the change in the diameter of carbide in matrix since the change in $n$-value of steel B was different from that of steel A at the smaller carbide diameter.

To clarify the determination factor of $n$-value, Fig. 15 shows $n$-value as a function of carbide density in matrix. The density was calculated as $V c / d^{3}$; where $V c$ is the volume fraction of carbides in matrix and $d$ is the mean diameter of carbide in matrix. $N$-value decreased linearly with $V c / d^{3}$. Excess boron decreased $n$-value irrespective of the $V c / d^{3}$. The difference of $n$-value between steel A and steel $\mathrm{B}$ was at a constant level under any $V c / d^{3}$ so that $n$-value is considered to be determined by the carbide density in matrix, rather than the carbide diameter. Furthermore, this difference of $n$-value between steel A and steel B indicates that excess boron decrease $n$-value irrespective of fine carbides precipitated in matrix.

As shown in Figs. 7 and 8, the difference of $m$-value was the maximum at lower over-aging temperature at which the difference of the carbide volume fraction between steel A and steel $\mathrm{B}$ was the minimum. Considering the change in the carbide diameter in Fig. 6, this indicates that the carbide diameter affects $m$-value strongly rather than the carbide volume fraction. To make clear the cause of the change in $m$-value, a cross section of the vicinity of the fractured portion after tensile test was observed by using scanning electron microscope. A few voids, which are pointed out by arrows in Fig. 16, were observed at the interface between carbides and matrix. Since the voids generated at the interface between matrix and grain boundary carbides, it can be considered that post-uniform elongation is governed by the morphology of carbides at the grain boundaries. Figure 17
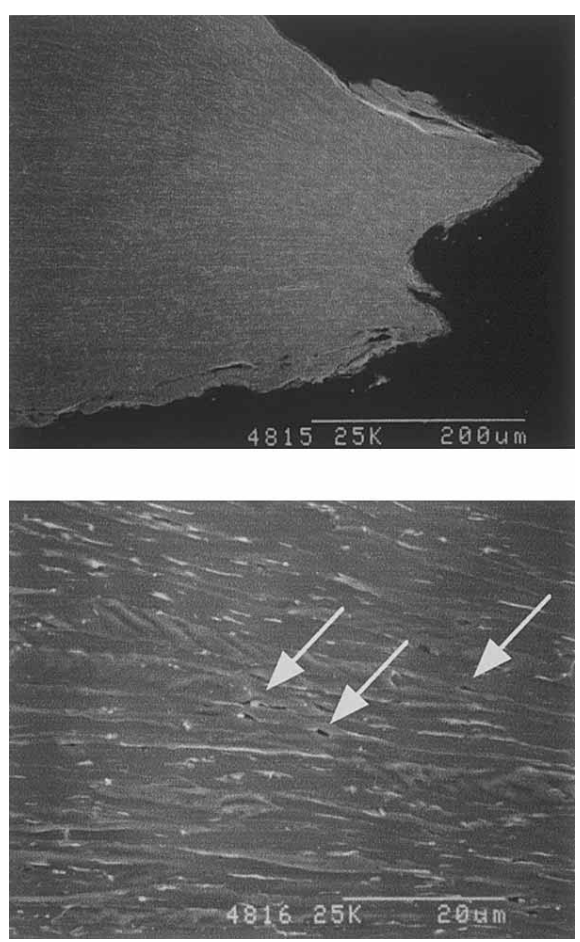

Fig. 16. Scanning electron micrographs showing voids near the fracture point of tensile specimen in the over-aged at $300^{\circ} \mathrm{C}$.

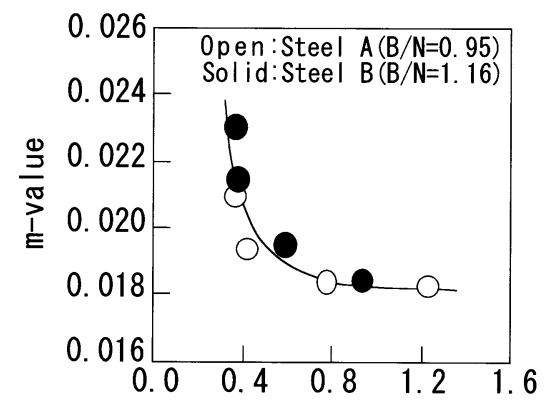

Carbide diameter at grain boundary $(\mu \mathrm{m})$

Fig. 17. Effect of diameter of carbide at grain boundary on $m$ value of boron-bearing Al-killed steel sheet.

shows the change in $m$-value as a function of the mean diameter of carbide at the grain boundary. It is seemed that $m$-value is governed by the carbide diameter irrespective of the small amount of excess boron in this study. The relationship between the carbide diameter and $m$-value is different from that in the previous work ${ }^{6}$ since carbides at the grain boundaries were distinguished from those in matrix in this study. This indicates that only carbides at the grain boundaries strongly affect $m$-value. The remarkable improvement of $m$-value in the small carbide diameter may be caused by the fact that the interfacial area between carbides and matrix decrease dramatically with the carbide diameter.

Considering the substantial effects of carbide morphology on the elongation of continuously annealed boron-bearing Al-killed steel sheet, as discussed above, excess boron is not desirable for uniform elongation because it makes fine carbides precipitated in matrix, which deteriorates $n$ value. However, excess boron is desirable for improving post-uniform elongation because it suppresses carbide precipitation at the grain boundaries. 


\section{Conclusions}

The effects of size and precipitation site of carbides on tensile properties of continuously annealed boron-bearing Al-killed steel sheet have been studied. The results obtained are summarized as follows:

(1) Both mean diameter and size distribution of carbides decrease with the over-aging temperature. The minimum carbide diameter is around $0.4 \mu \mathrm{m}$ in the steels overaged at $300^{\circ} \mathrm{C}$ regardless to the alloying of boron.

(2) The carbide precipitation site changes from the grain boundaries to matrix with a decrease in the overaging temperature. Almost all of carbides precipitate in matrix when the materials are water quenched before the overaging treatment.

(3) Excess boron accelerates carbide precipitation at $\mathrm{BN}$ precipitates in matrix. The reason for this may be preliminary segregation of boron at the grain boundaries.

(4) Elongation of boron-bearing Al-killed steel sheet is influenced by carbon in solution, carbide morphology and excess boron in solution. Especially, elongation is deteriorated by excess boron under the same amount of carbon in solution.

(5) By evaluating $n$-value as a function of the carbide density in matrix $\left(V c / d^{3} ; V_{c}\right.$ : carbide volume fraction, $d$ : mean diameter of carbide in matrix), $n$-value decrease with increasing $V c / d^{3}$. Excess boron in solution deteriorates $n$ value regardless of the carbide density in matrix.

(6) $M$-value is improved remarkably in small carbide diameter irrespective of small amount of excess boron. This can be attributed to generation of voids at interface between matrix and grain boundary carbides.

\section{REFERENCES}

1) N. Takahashi, M. Shibata, Y. Furuno, H. Hayakawa, K. Kakuta and K. Yamamoto: Conf. Proc. on Technology of Continuous Annealed Cold-Rolled Sheet Steel, TMS-AIME, Warrendale, PA, (1984), 133.

2) R. Pradhan: Conf. Proc. on Technology of Continuous Annealed Cold-Rolled Sheet Steel, TMS-AIME, Warrendale, PA, (1984), 185.

3) M. Sudo and I. Tsukatani: Conf. Proc. on Technology of Continuous Annealed Cold-Rolled Sheet Steel, TMS-AIME, Warrendale, PA, (1984), 203.

4) P. Messien and V. Leroy: Steel Res., 60 (1989), 320.

5) S. Watanabe and H. Ohtani: Tetsu-to-Hagané, 62 (1976), 14

6) Y. Hosoya, H. Kobayashi, T. Shimomura, K. Matsudo and K. Kurihara: Conf. Proc. on Technology of Continuous Annealed ColdRolled Sheet Steel, TMS-AIME, Warrendale, PA, (1984), 61.

7) R. Pradhan and J. J. Battisti: Conf. Proc. on Hot-\&Cold-Rolled Sheet Steels, TMS-AIME, Warrendale, PA, (1988), 41.

8) Y. Hosoya, S. Hashimoto and A. Nishimoto: Conf. Proc. on Effects of Load and Thermal histories on Mechanical Behavior of Materials, TMS-AIME, Warrendale, PA, (1987), 273.

9) N. Takahashi, M. Abe, O. Akisue and H. Katoh: Conf. Proc. on Metallurgy of Continuous-annealed Sheet Steel, TMS-AIME, Warrendale, PA, (1982), 51.

10) H. Katoh, K. Koyama and K. Kawasaki: Conf. Proc. on Technology of Continuous Annealed Cold-Rolled Sheet Steel, TMS-AIME, Warrendale, PA, (1984), 79.

11) J. H. Holloman: Trans. TMS-AIME, 162 (1945), 268.

12) A. K. Ghosh: Metall. Trans, 5 (1974), 1607.

13) K. Kimura and K. Nakaoka; Tetsu-to-Hagané, 68 (1982), S586.

14) M. Ueno and T. Inoue: Trans. Iron Steel Inst. Jpn., 13 (1973), 211.

15) E. T. Stephenson: Trans. Am. Soc. Met., 55 (1962), 624. 